\title{
SISTEMAS DE AMORTECIMENTO DE CHEIAS DO PARQUE DAS ACÁCIAS NA CIDADE DE UBERABA (MG)
}

\author{
Marcos Fernandes Silva ${ }^{1}$ \\ Diego de Souza Sardinha² \\ Patrícia Diniz Martins ${ }^{3}$ \\ Cristiano Poleto ${ }^{4}$
}

\begin{abstract}
RESUMO: A cidade de Uberaba é uma cidade em constante crescimento, sendo a $8^{\text {a }}$ cidade mais populosa do estado mineiro. Várias ações por parte da prefeitura municipal visam reduzir o impacto da crescente urbanização da referida cidade, que sofre frequentes inundações em sua área central. Nesse âmbito, foi proposto o Projeto Água Viva I e II, amparados pelos pelo PAC (I e II) do Governo Federal e pelo BID (Banco Interamericano do Desenvolvimento), com a finalidade de ampliação do sistema de macrodrenagem na área central o de microdrenagem nas áreas adjacentes. Como contrapartida no projeto, a Prefeitura Municipal construiu o sistema de amortecimento de Cheias do Parque das Acácias, composto por dois reservatórios que visam reter parte da vazão de pico, evitando assim que ela escoe para a área central minimizando o efeito das enchentes. O objetivo do presente artigo é analisar as vazões do reservatório principal do sistema de amortecimento de cheias no Parque das Acácias e a influência imposta na área central da cidade. Como resultados podem ser destacados que a liberação da água pelos reservatórios é constante, ocorre à retenção do volume excedente que entra no reservatório principal e seu nível se eleva. Quando sua capacidade máxima de retenção é atingida, a água escoa por um sistema emergencial de ladrões e começa a elevar o nível do segundo reservatório. Com isso ocorre uma amortização das cheias na área central da cidade, pois um volume que se deslocaria todo de uma vez para as galerias centrais é liberado gradativamente no sistema de macrodrenagem. Mesmo assim, já ocorreram precipitações na área com a presença de inundações, sendo que o projeto implementado apenas minimizou os efeitos, não dando uma solução definitiva para o problema.
\end{abstract}

Palavras-Chave: Enchentes. Drenagem Urbana. Planejamento Urbano.

1 - Graduando em Engenharia Ambiental - Universidade Federal do Triângulo Mineiro (UFTM). markimfsv@hotmail.com

2 - Engenheiro Ambiental pelo Instituto de Ensino Superior COC de Ribeirão Preto (SP). É mestre e doutor em Geologia Regional pelo Instituto de Geociências e Ciências Exatas da Universidade Estadual Paulista Júlio de Mesquita Filho de Rio Claro (SP). Atualmente é Professor Adjunto do Instituto de Ciência e Tecnologia (ICT) da Universidade Federal de Alfenas (Unifal) - Campus avançado de Poços de Caldas (MG). diegosardinha@yahoo.com.br

3 - Engenheira Ambiental - $\mathrm{M}^{\mathrm{a}}$ Recursos Hídricos Energéticos e Ambientais -UFTM: Instituto de Ciências Tecnológicas e Exatas (ICTE). patricia_ambiental@hotmail.com

4 - Engenheiro Civil - PhD em Recursos Hídricos e Meio Ambiente - Universidade Federal do Rio Grande do Sul (UFRGS): Instituto de Pesquisas Hidráulicas (IPH). cristiano_poleto@hotmail.com 


\section{INTRODUÇÃO}

A busca pela qualidade de vida no mundo hoje vem se tornando cada vez mais de suma importância nas grandes cidades. Melhorar a qualidade de vida é uma tarefa que envolve diversos fatores, muitos deles relacionados ao saneamento básico urbano que nas ultimas décadas tem se destacado.

O saneamento básico urbano envolve basicamente a coleta de resíduos sólidos urbanos, tratamento de água e esgoto e drenagem urbana, visando melhorar a qualidade de vida da população.

Hoje no Brasil há um grande desenvolvimento das áreas metropolitanas juntamente com seus polos industriais que trazem grandes benefícios diretos e indiretos para a comunidade. Porém esse grande desenvolvimento traz também malefícios, sendo um dos principais a explosão demográfica da população, implicando seu crescimento desordenado que não é acompanhado pelo estabelecimento de estruturas básicas como coleta de esgotos e fornecimento de água tratada, mostrando que uma cidade bem projetada e com controle urbanístico não é só uma necessidade, mas a única forma sustentável de se viver.

A maior parte das cidades que surgiram durante a era colonial se desenvolveram nas margens dos rios e em vales acidentados devido ao fato da população precisar de acesso fácil aos recursos hídricos existentes para o desenvolvimento das atividades rotineiras da época. Com o passar do tempo, essas cidades foram se desenvolvendo de forma desordenada, e então na década de 80 ocorreu grande pavimentação das vias públicas e canalização dos córregos existentes nas cidades.

Em Uberaba, essa realidade não foi diferente, sendo que todos os córregos que cortam a área central da cidade foram canalizados por meio de galerias submersas e todas as vias pavimentadas, sendo todo o volume precipitado pelas chuvas deslocado para o centro da cidade.

Por esse motivo, na presença de fortes precipitações ocorrem fortes inundações na área central da cidade já que as galerias existentes não conseguem escoar todo o volume de água deslocado para o centro.

Com isso foi proposta a instalação de um sistema de amortecimento de cheias na cidade e a ampliação do sistema de macrodrenagem e microdrenagem na área central, além da ampliação do serviço de coleta de efluentes a fim de diminuir os impactos ambientais causados sobre a área e evitar a proliferação de doenças de veiculação hídrica. 


\section{OBJETIVO}

Analisar as vazões do reservatório principal do sistema de amortecimento de cheias no Parque das Acácias e a influência imposta na área central da cidade.

\section{CARACTERIZAÇÃO DA AREA DE ESTUDO}

Uberaba é uma cidade localizada na região do Triângulo Mineiro com aproximadamente 300.000 habitantes, assolada por frequentes inundações na área central. A geomorfologia da área central é marcada pela incidência de áreas com elevada declividade aliada à alta taxa de impermeabilização que potencializam a ação do escoamento superficial, transportando um grande volume em um curto espaço de tempo para áreas mais baixas, onde se localizam as avenidas principais. Como o sistema atual de microdrenagem não consegue escoar o volume solicitado, ocorre à formação de enchentes na área central da cidade.

Com o intuito de solucionar essa questão, a prefeitura municipal de Uberaba, amparado pelo Programa de Aceleração do Crescimento (PAC I e II) propôs o projeto AGUA VIVA. Esse projeto consiste na ampliação do sistema de microdrenagem e macrodrenagem existente, construindo-se uma terceira galeria subterrânea e na implantação de interceptores de esgotos que irão conduzir a parcela de efluentes da cidade que não é tratada, sendo jogado in natura no rio Uberaba.

Como contra partida no projeto, a Prefeitura Municipal de Uberaba propôs a criação de um sistema de amortecimento de cheias denominado de Parque das Acácias. Esse sistema é composto por 02 reservatórios para acumulação de água durante eventos extremos de precipitação na área, além de contar com pistas de caminhadas, quiosques, quadras poliesportivas, academia ao ar livre, pista de skate propício para o desenvolvimento de atividades físicas, como pode ser visualizado na Figura 01. 


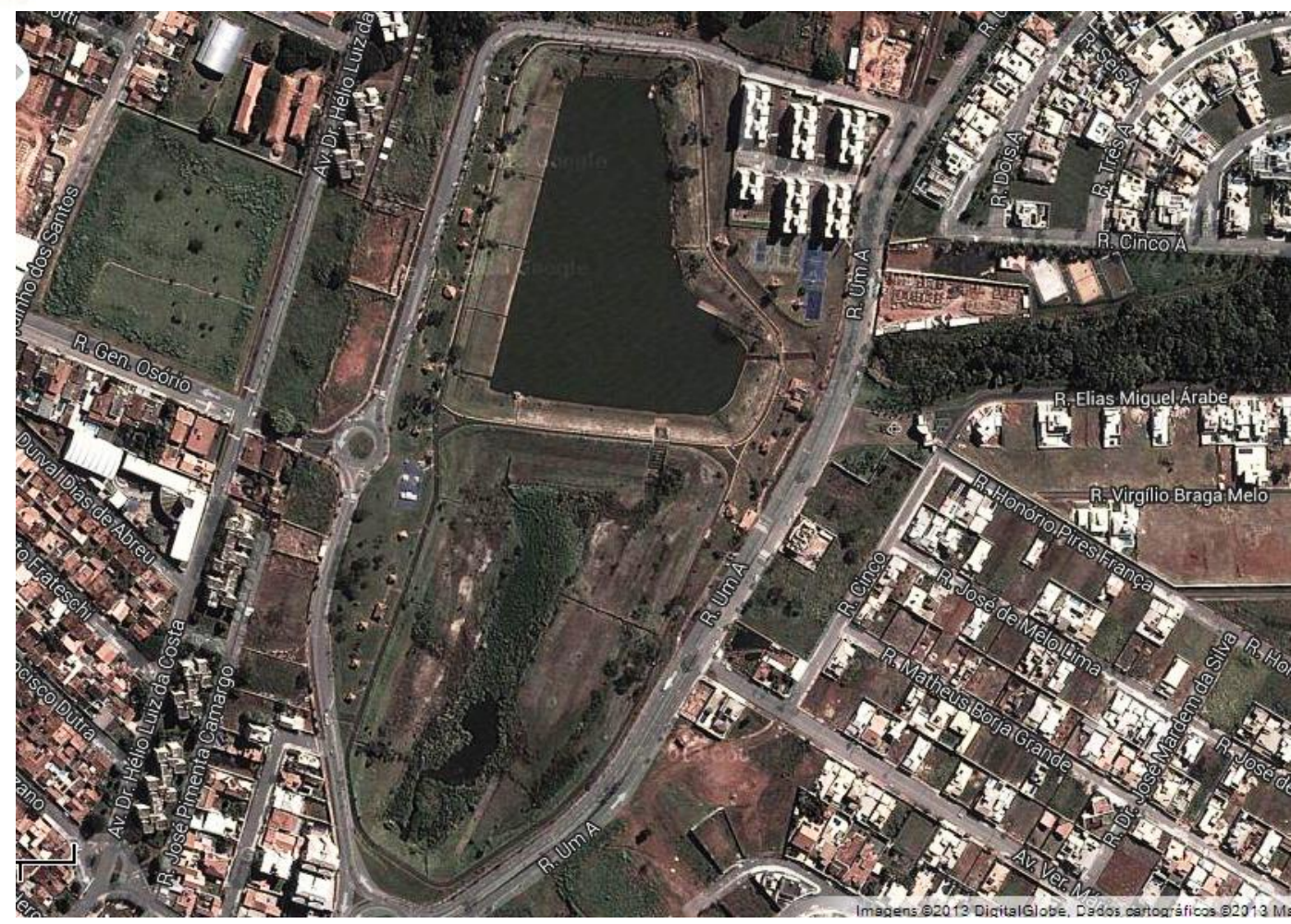

Figura 01: Imagem de satélite do parque das Acácias em Uberaba, Minas Gerais. Fonte: Google Earth

O reservatório do Parque das Acácias possui uma área de aproximadamente 70.000 $\mathrm{m}^{2}$ e situa-se entre os paralelos $19^{\circ} 44^{\prime} 51^{\prime \prime}$ e $19^{\circ} 45^{\prime} 11^{\prime \prime}$ de latitude $S$ e meridianos $47^{\circ} 54^{\prime} 50^{\prime \prime}$ e $47^{\circ} 54^{\prime} 52^{\prime \prime}$ longitude W, na região oeste do Estado de Minas Gerais. O reservatório, localizado no bairro Parque do Mirante município de Uberaba, é formado pelas duas nascentes do Córrego Santa Rita.

Os pontos de coleta foram distribuídos na área com a finalidade de quantificar o volume que entra no reservatório principal do sistema de amortecimento e o volume que sai dele, como pode ser visualizado na Figura 02. 

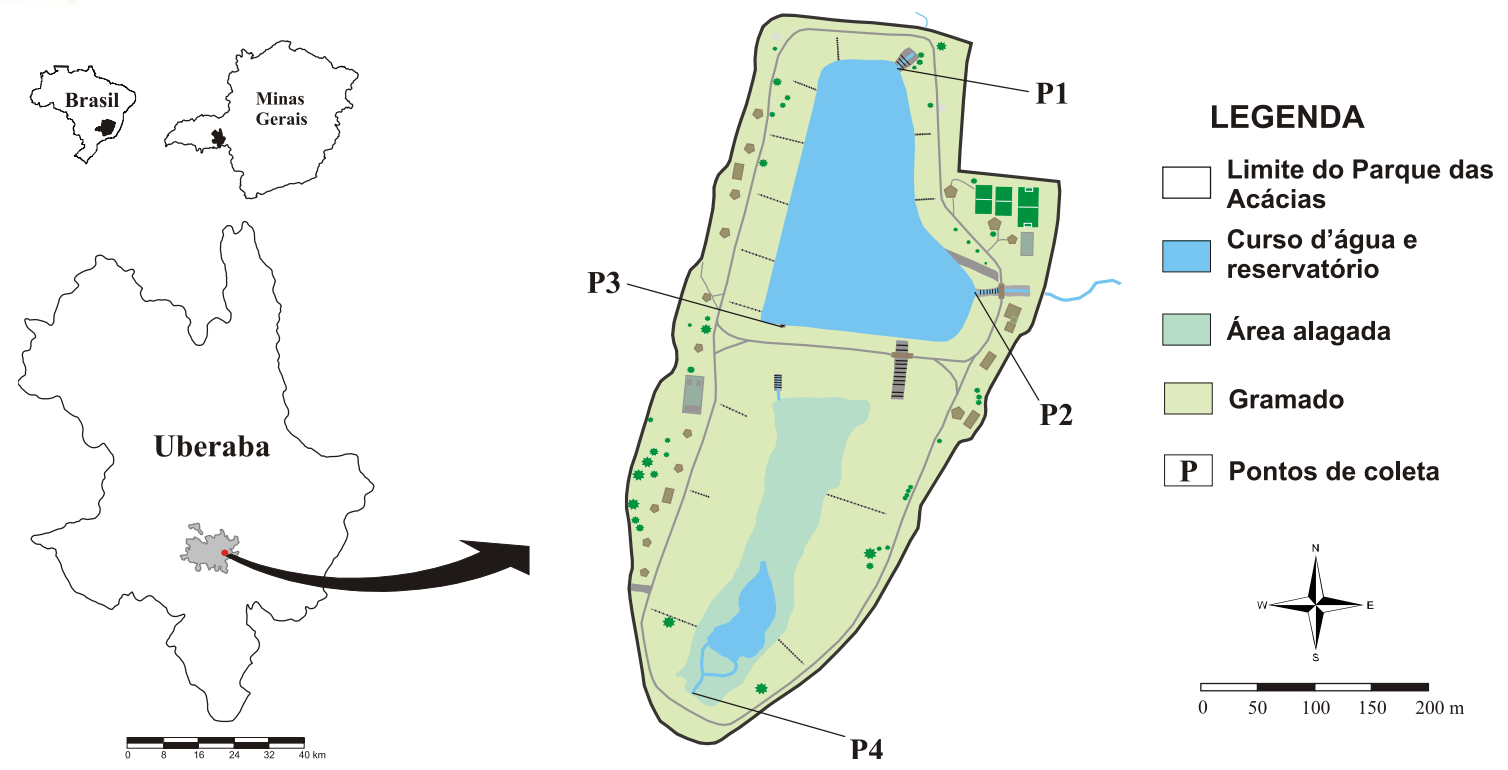

Figura 02. Localização e pontos de amostragem no reservatório do Parque das Acácias.

Segundo o sistema de Köppen, a região do município Uberaba está submetida a um clima tropical chuvoso do tipo Aw, ou seja, de inverno seco e verão úmido. As estações são bem definidas, apresentando clima frio e seco durante o inverno e clima quente e úmido durante o verão. A precipitação média de dezembro, o mês mais chuvoso, é de 276 $\mathrm{mm}$ e agosto o menos chuvoso com $11 \mathrm{~mm}$ (Figura 03). A vegetação original era constituída por cerrado, cerradão e campo cerrado, hoje restrita a uma faixa descontínua as margens do curso do Córrego das Lajes, já próximo ao exutório com o Rio Uberaba. 


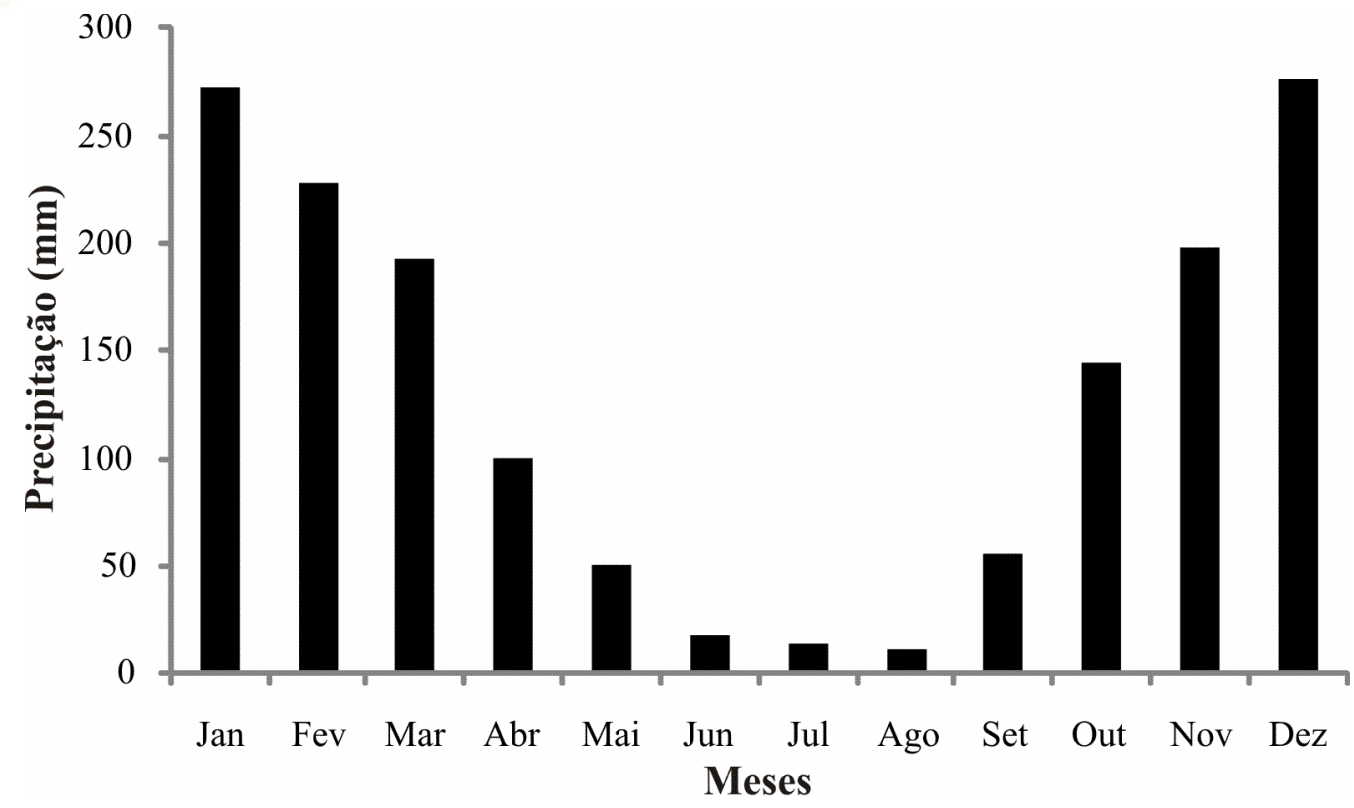

Figura 03. Precipitação média mensal entre os anos de 1914 e 1994 em Uberaba (MG). Fonte: Prefeitura Municipal de Uberaba, 2009.

Ocorre na área do reservatório do Parque das Acácias a unidade da Bacia do Paraná pertencente ao Grupo Bauru (Formação Uberaba). A Formação Uberaba é formada por arenitos muito finos a lamitos siltosos, arenitos finos subordinados, com matriz argilosa, incluindo grande quantidade de materiais de retrabalhamento de rochas ígneas efusivas e intrusivas básicas, ultrabásicas e intermediárias, alcalinas ou não (Hasui, 1968). Do solo que recobre a área, o dominante é definido como Latossolo Vermelho Amarelo textura média e textura argilosa. 


\section{LEGENDA}
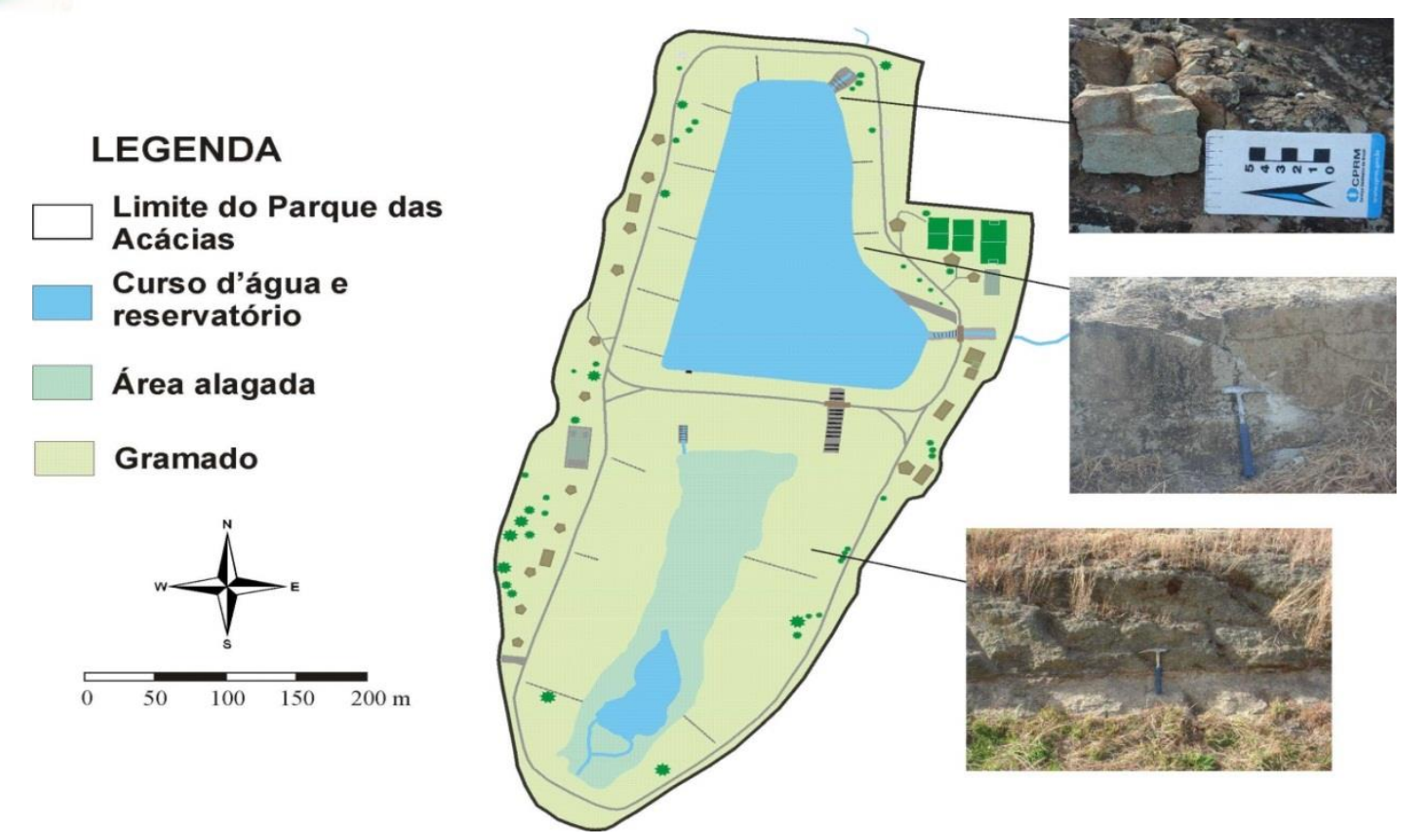

Figura 04: Afloramentos rochosos da Formação Uberaba no Parque das Acácias.

\section{USO E OCUPAÇÃO DO SOLO}

A cidade de Uberaba, localizada na Bacia Hidrográfica do Rio Uberaba, apresentou ocupação entorno desse importante rio, que abastece a cidade até os dias atuais, desenvolvendo dentro da microbacia do córrego das Lajes, que se encontra canalizadas na área central da cidade, e é afluente do Rio Uberaba.

A evolução na ocupação e uso do solo impõe inúmeras interferências no meio, como retirada da cobertura vegetal, aumento da impermeabilização do solo, reestruturação do solo para construções civis, por meio de terraplanagem e compactação, erosões do solo, lixiviação dos minerais existentes, entre outros. Outro fator preocupante é o aumento da poluição que se gera com o aumento da população, por meio de dejetos que muitas das vezes são descartados de forma incorreta no meio ambiente, gerando grandes impactos tanto na flora e fauna, quanto na saúde da população.

A ocupação no entorno do Parque das Acácias é um fator recente, no qual se tem a implantação de inúmeros condomínios e bairros residenciais. Por se tratar de uma área considerada calma, grande valor econômico foi agregado no entorno do parque, caracterizando uma população de nível social mais elevado.

Grandes obras de pavimentação, construção de galerias pluviais, impermeabilização dos solos dentro dos condomínios por meio da construção de calçadas, também presentes no entorno do parque influenciam diretamente na capacidade de absorção de água da 


\section{Thent Fórum Ambiental

chuva pelo solo, sendo ela transportada diretamente para os reservatórios do Parque, como pode ser visualizado na Figura 04.

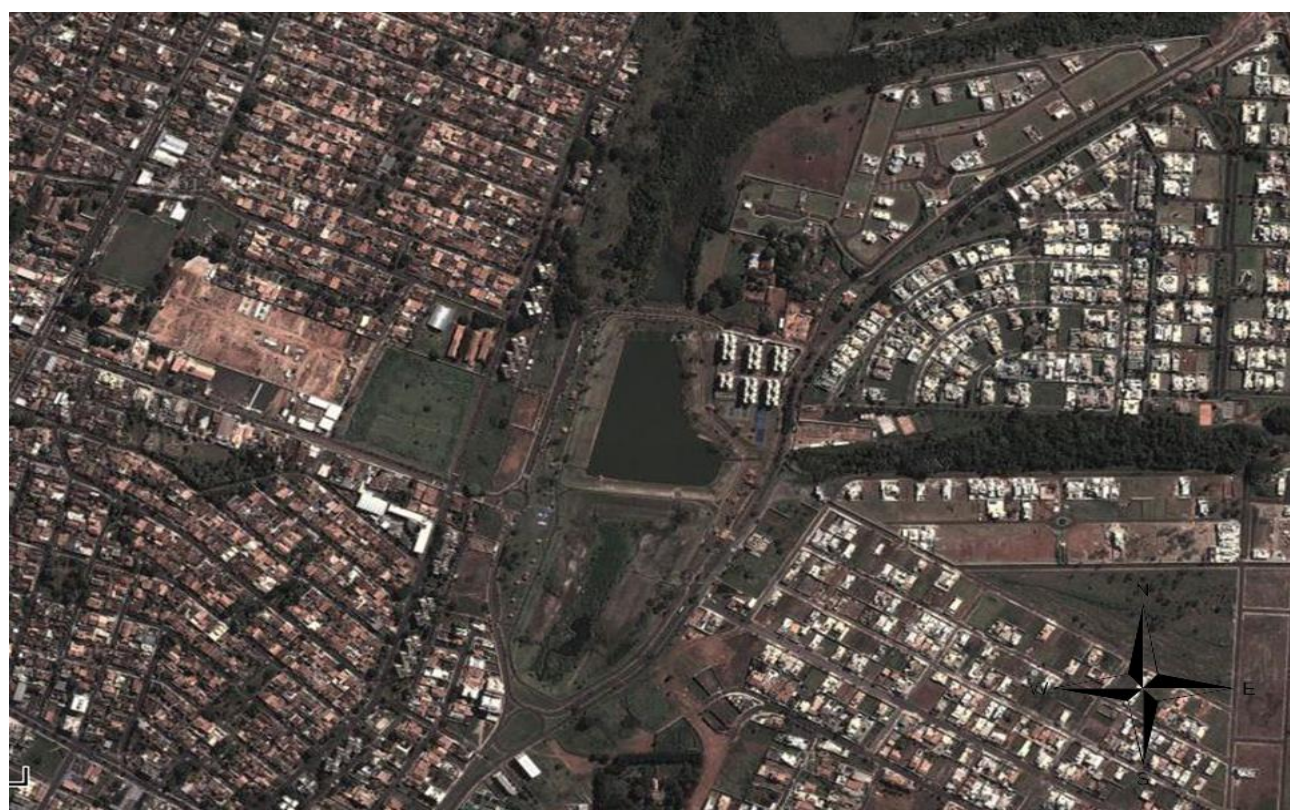

Figura 04: Área de Influencia do Sistema de Drenagem do Parque das Acácias. Fonte: Google maps.

Junto as nascentes do Córrego Santa Rita, ainda prevalecem à presença de sítios e chácaras, mas que devido a grande expansão que ocorre no local, futuramente podem não existir, passando a predominar uma realidade que se convive no centro da cidade (canalização do leito natural do rio, o que influencia diretamente na velocidade de escoamento das águas, ocasionando enchentes).

Toda a porção leste, oeste e norte das áreas ao arredores do Parque é drenada pelo sistema de amortecimento de cheias presente no local. Além disso, existem sistemas de microdrenagem que drenam a águas pluviais em áreas mais distantes do parque, e conduzem o volume drenado para os reservatórios por meio de sistema de tubulação e escoamento livre.

A área de drenagem do sistema de amortecimento de cheias tem como finalidade reter parte da água precipitada, evitando que toda essa água escoe de uma vez para área central, o que aumenta a vazão de pico e agrava assim as enchentes. Uma exemplificação do processo de amortecimento se encontra disposto na Figura 05. 


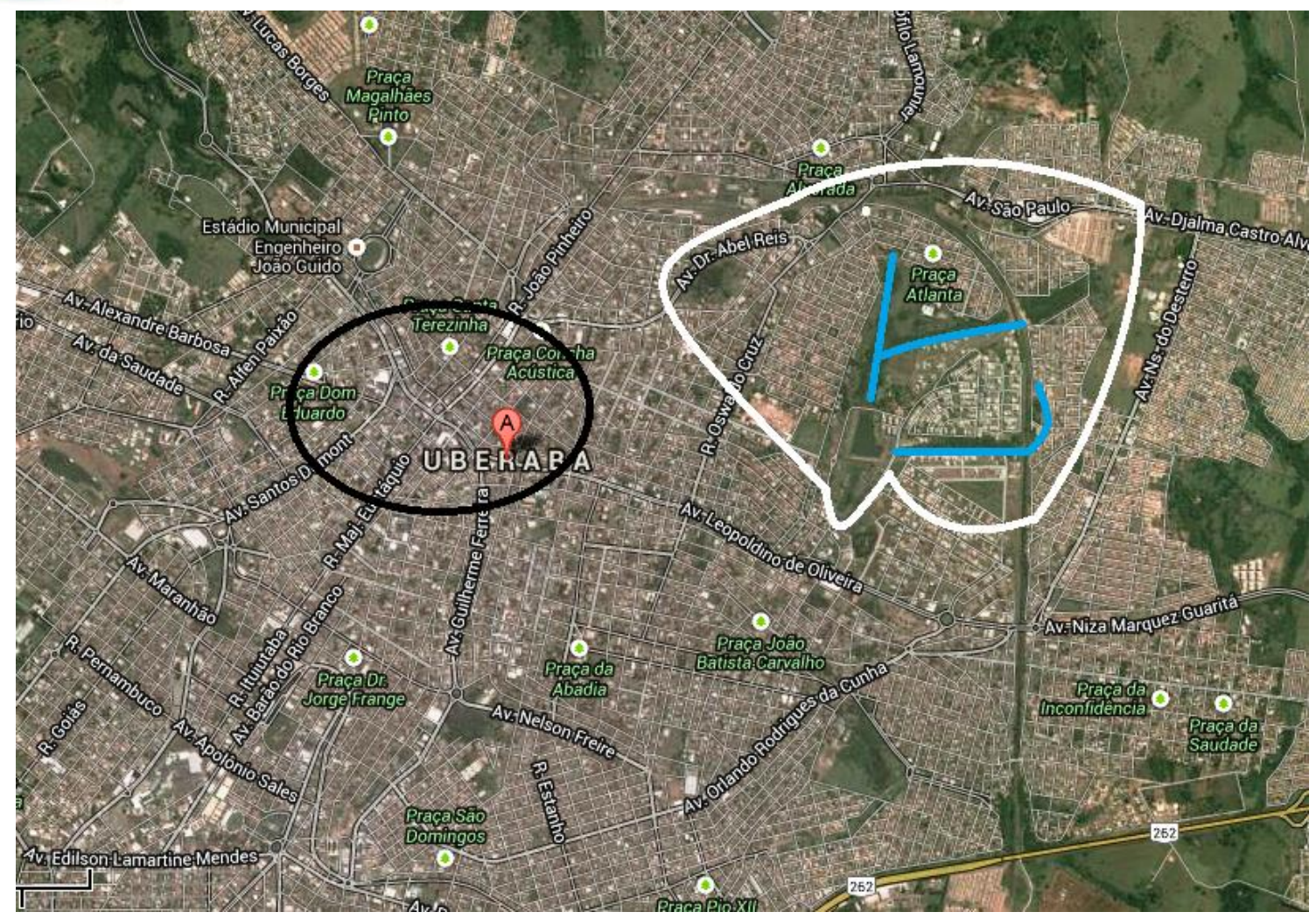

Figura 05: Influencia do sistema de amortecimento de cheias do Parque das Acácias.

Fonte: Google maps. Adaptação: Autores.

A área contida no círculo branco é dada pela área de drenagem do sistema de amortecimento de cheias do Parque das Acácias. Toda essa área é drenada pelo sistema de microdrenagem que se encontra na área, onde a água é conduzida por meio de manilhas para reservatório principal do sistema de amortecimento de cheias.

Nas áreas mais próximas do parque onde ocorre o deslocamento superficial do volume precipitado, esse se desloca rumo aos reservatórios pela própria geomorfologia do local e entram nele por meio de escadas hidráulicas.

Como a liberação da água pelos reservatórios é constante, ocorre à retenção do volume excedente que entra no reservatório principal e seu nível se eleva. Quando a capacidade máxima de retenção é atingida, a água escoa por um sistema emergencial de ladrões e começa a elevar o nível do segundo reservatório. Com isso ocorre uma amortização das cheias na área central da cidade, pois um volume que se deslocaria todo de uma vez para as galerias centrais é liberado gradativamente no sistema de macrodrenagem.

Em casos extremos de precipitação, caso o reservatório emergencial venha a atingir sua capacidade máxima de retenção, ocorrerá então à saída da água por um sistema de 
esvaziamento emergencial que injetará todo o volume que entre no reservatório nas galerias, evitando assim um colapso do sistema de amortecimento, sendo que um fenômeno dessa magnitude nunca foi presenciado em Uberaba.

\section{MATERIAS E MÉTODOS}

As imagens dispostas foram obtidas a partir de fotografias aéreas, imagens de satélite e documentos cartográficos existentes, além de controle em campo. $O$ levantamento de campo para a tomada de coordenadas geográficas foi feito utilizando equipamento GPS (Global Positioning System) eTrex Vista H da Garmin. Quanto aos aspectos climatológicos, foram obtidos os valores da temperatura média do ar e precipitação mensais durante o período de estudo, bem como dados históricos. Estes dados foram levantados e pleiteados junto a ANA (Agência Nacional de Águas) e INMET (Instituto Nacional de Meteorologia). Para a plotagem dos gráficos com os resultados obtidos foi utilizado o software Microsoft Office Excel 2007.

Para a realização do projeto no Parque das Acácias, foram selecionados quatro pontos para coleta de água para análise da vazão. A localização de cada ponto está descrito na Tabela 2 e na Figura 3.

Tabela 2 - Coordenadas geográficas dos Pontos de Coleta

\begin{tabular}{ccc}
\hline $\begin{array}{c}\text { Ponto } \\
\text { s }\end{array}$ & $\begin{array}{c}\text { Coordenadas } \\
\text { geográficas }\end{array}$ & Referencias \\
& $\boldsymbol{S}$ & $\boldsymbol{W}$ \\
P1 & $19^{\circ} 44^{\prime} 86^{\prime \prime}$ & Córrego Santa Rita, afluente principal do \\
& $47^{\circ} 54^{\prime} 75^{\prime \prime}$ & reservatório. \\
P2 & $19^{\circ} 44^{\prime} 97^{\prime \prime}$ & Córrego Santa Rita, afluente esquerdo do \\
& $47^{\circ} 54^{\prime} 70^{\prime \prime}$ & reservatório. \\
P3 & $19^{\circ} 44^{\prime} 59^{\prime \prime}$ & Exultório do Reservatório 01. \\
& $47^{\circ} 54^{\prime} 49^{\prime \prime}$ & \\
P4 & $19^{\circ} 45^{\prime} 10^{\prime \prime}$ & Após Área Alagada. \\
\hline
\end{tabular}

Para o cálculo da vazão em todos os pontos de amostragem utilizou-se da metodologia descrita por (Hermes \& Silva, 2004). Assim utilizou-se uma régua limnimétrica de leitura da medida do nível do rio, uma trena, objeto flutuador e um cronômetro, sendo as variáveis colocadas posteriormente na seguinte fórmula para obtenção da vazão:

$$
Q=\frac{A x D x C}{T}
$$

Onde: 
$Q=\operatorname{vazão~}\left(\mathrm{m}^{3} / \mathrm{s}\right)$;

$A=$ Área da seção transversal do rio $\left(\mathrm{m}^{2}\right)$;

$D=$ Distância usada para medir a velocidade do rio $(m)$;

$C=$ Coeficiente de correção ( 0,8 para rios com fundo rochoso e 0,9 para rios com fundo lodoso);

$T=$ Tempo (s) gasto pelo objeto flutuador para atravessar a distância $D$.

\section{RESULTADOS}

\section{Ponto P1}

O ponto P1 é caracterizado por ser o afluente principal do reservatório do Parque das Acácias, e entra no reservatório por meio de uma galeria, onde as amostras eram aferidas, como pode ser visualizado na Figura 06, logo abaixo:

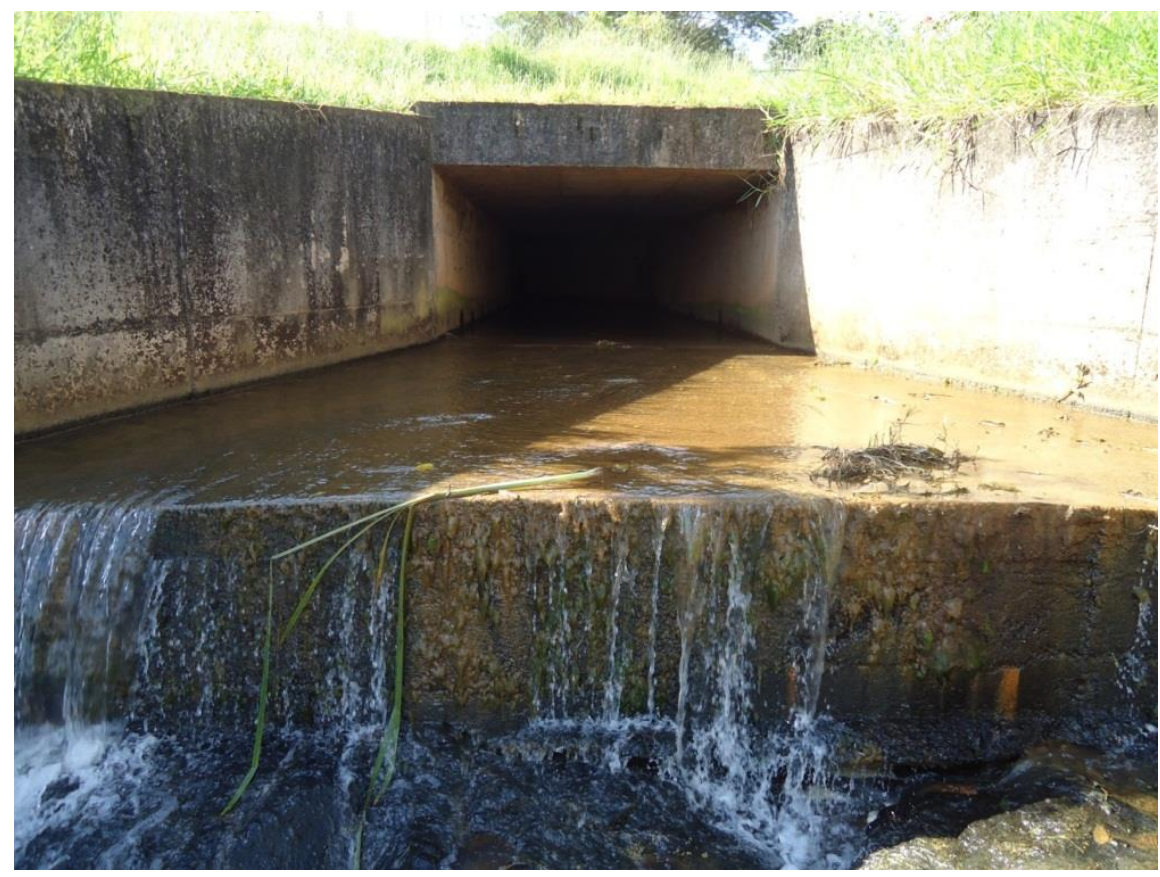

Figura 06 - Foto do Ponto de coleta P1.

Fonte: Autores.

Os resultados obtidos pelo método flutuador estão dispostos na Figura 07 abaixo: 


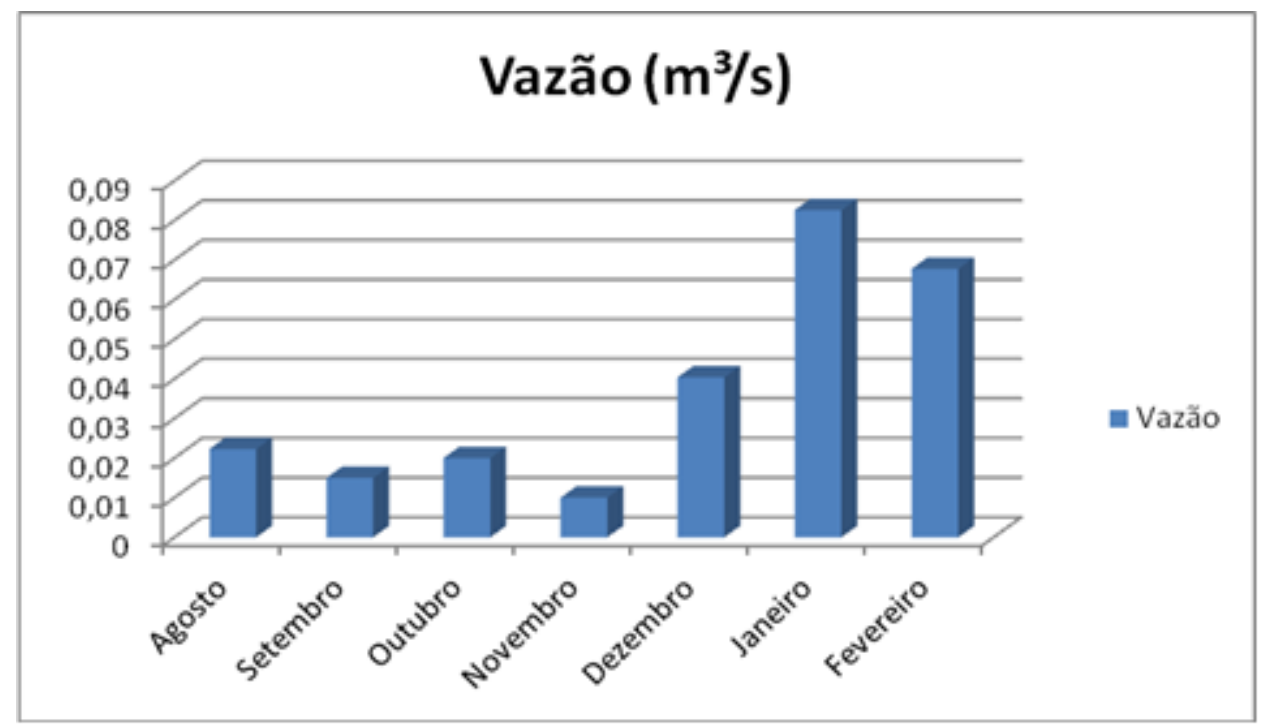

Figura 07: Dados de vazão obtidos no Ponto 01 Fonte: Autores.

Por esse afluente entra a maior parte do volume de água que escoa normalmente para o reservatório principal devido ao fato de ser a nascente principal do Córrego santa Rita, e ter boa parte da área de drenagem direcionada para ele. Observam-se os maiores valores de vazão em Janeiro, Fevereiro e Dezembro, sendo esses valores $0.0826 \mathrm{~m}^{3} / \mathrm{s}$, $0.0678 \mathrm{~m}^{3} / \mathrm{s}, 0.0404 \mathrm{~m}^{3} / \mathrm{s}$, respectivamente.

\section{Ponto P2}

O ponto P2 é caracterizado por ser o afluente secundário do reservatório do Parque das Acácias (Piscinão), e aflui ao reservatório por meio de uma galeria fluvial seguido de leito canalizado e escada hidráulica, onde as amostras eram aferidas, como pode ser visualizado na Figura 08. 


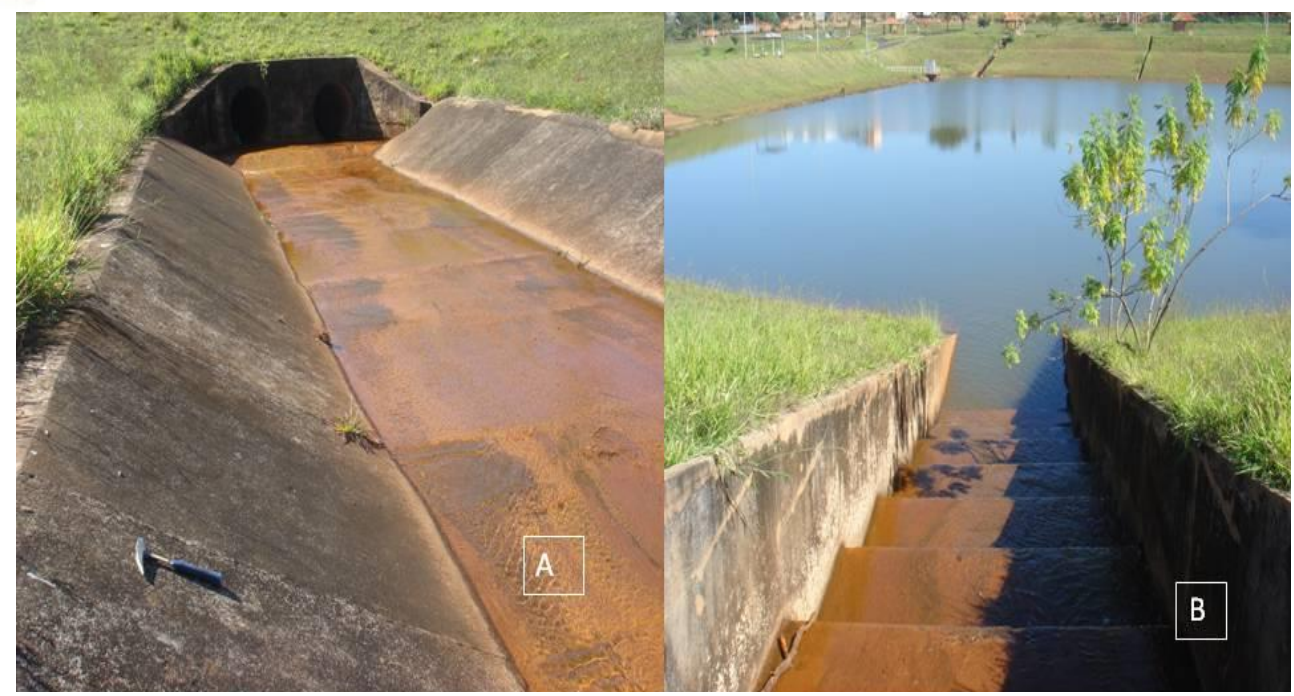

Figura 08 - A) Galeria e Leito Retificado. B) Escada Hidráulica.

Fonte: Autores.

Os resultados obtidos pelo método flutuador estão dispostos na Figura 09 abaixo:

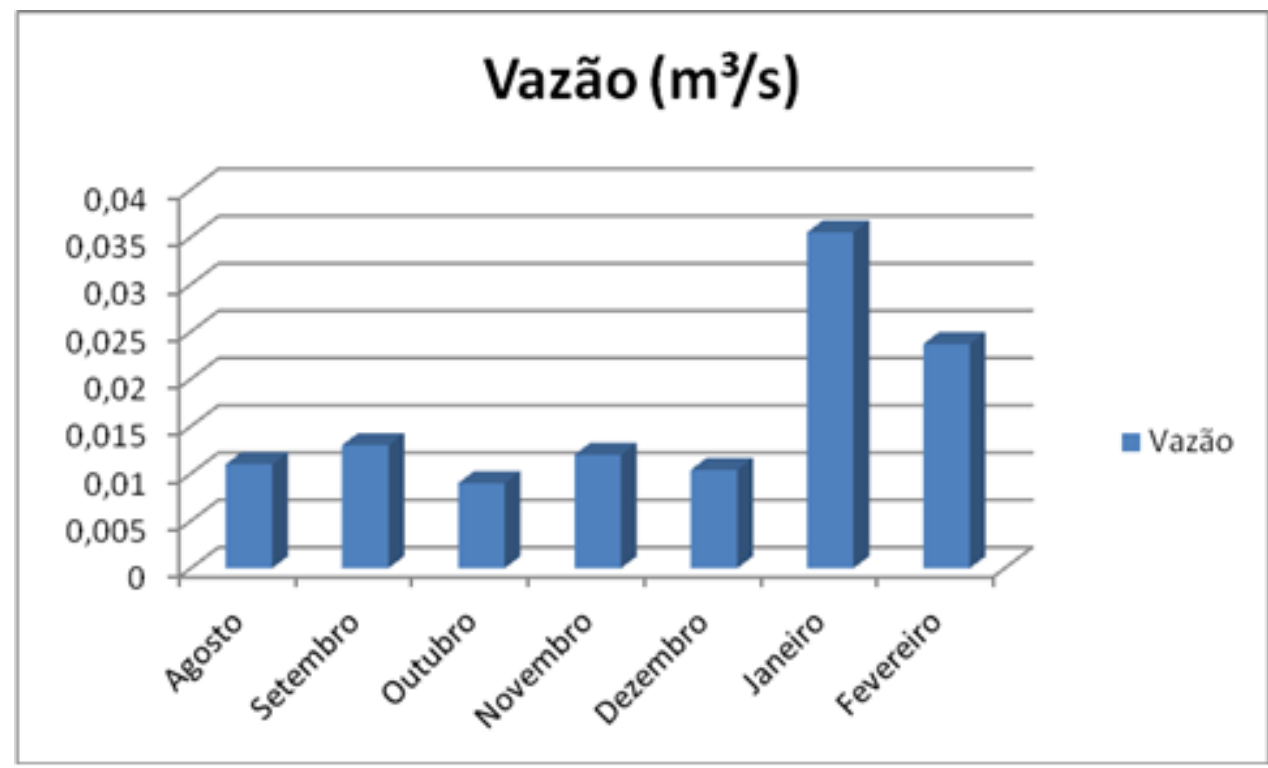

Figura 09: Dados de vazão obtidos no Ponto 01.

Fonte: Autores.

\section{Ponto P3}

O ponto P3 é caracterizado por ser o exutório do reservatório principal do Parque das Acácias, onde as águas drenam por galerias de leito canalizado e uma escada hidráulica, local aonde as amostras eram analisadas, como pode ser visualizado na Figura 10. 


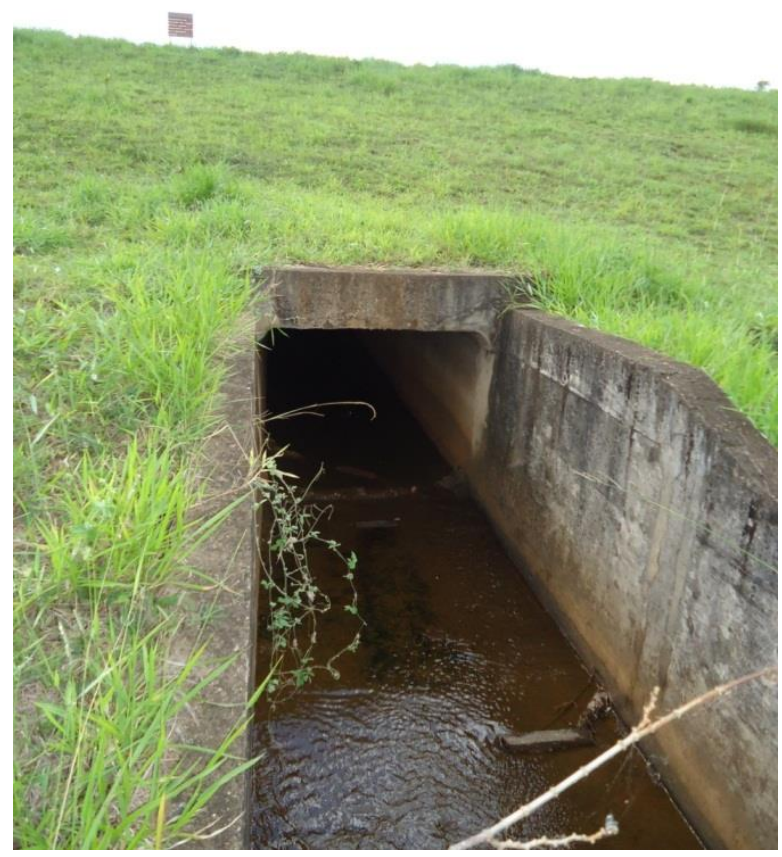

Figura 10 - Local do ponto de amostragem P3.

Fonte: Autores.

Os resultados obtidos pelo método flutuador estão dispostos na Figura 11, abaixo:

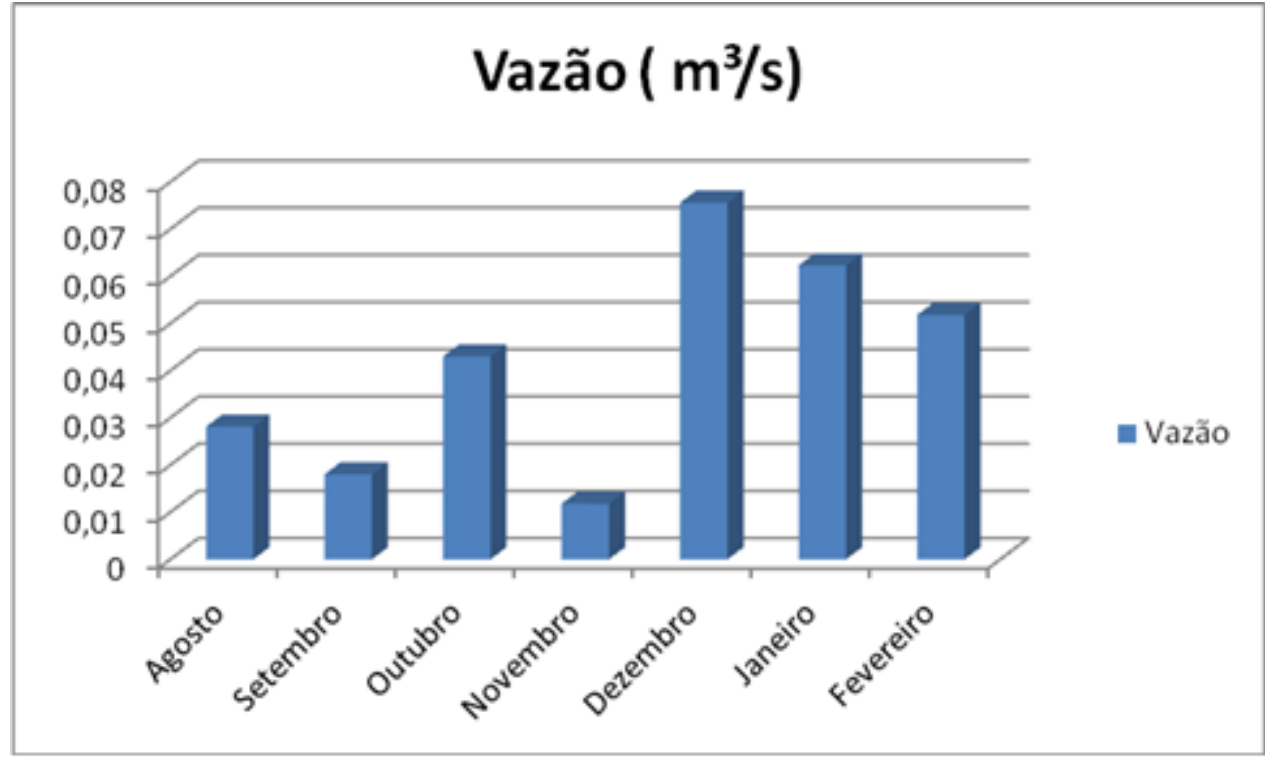

Figura 11: Dados de vazão obtidos no Ponto 01

Fonte: Autores. 


\section{Ponto P4}

O ponto P4 é caracterizado por estar após área alagada dento do reservatório emergencial no Parque das Acácias (Piscinão), aonde as amostras foram analisadas (Figura 12).

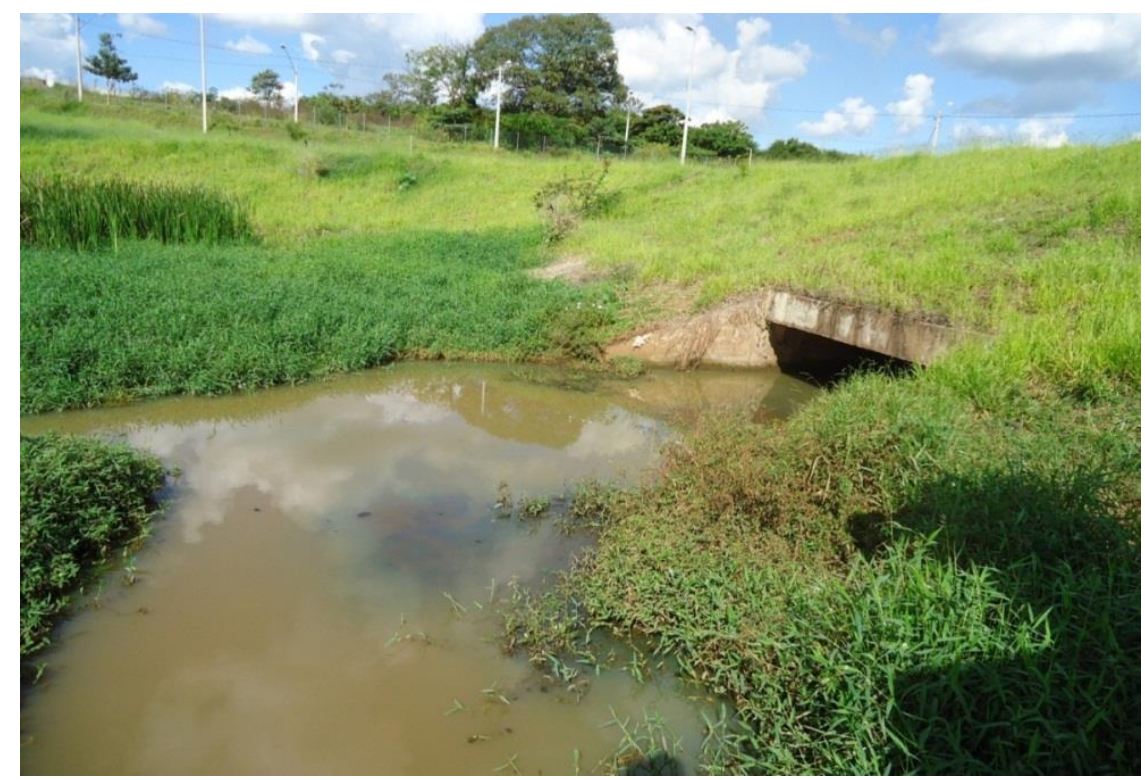

Figura 12 - Local de amostragem do ponto P4.

Fonte: Autores.

No ponto P4 por se tratar de um local de acumulação de água não foi possível calcular a vazão. O local é característico de locais pantanosos, presente em ecossistemas lênticos, como pode ser visualizado na Figura 13. 


\section{Periódica Eletrônica Fórum Ambiental

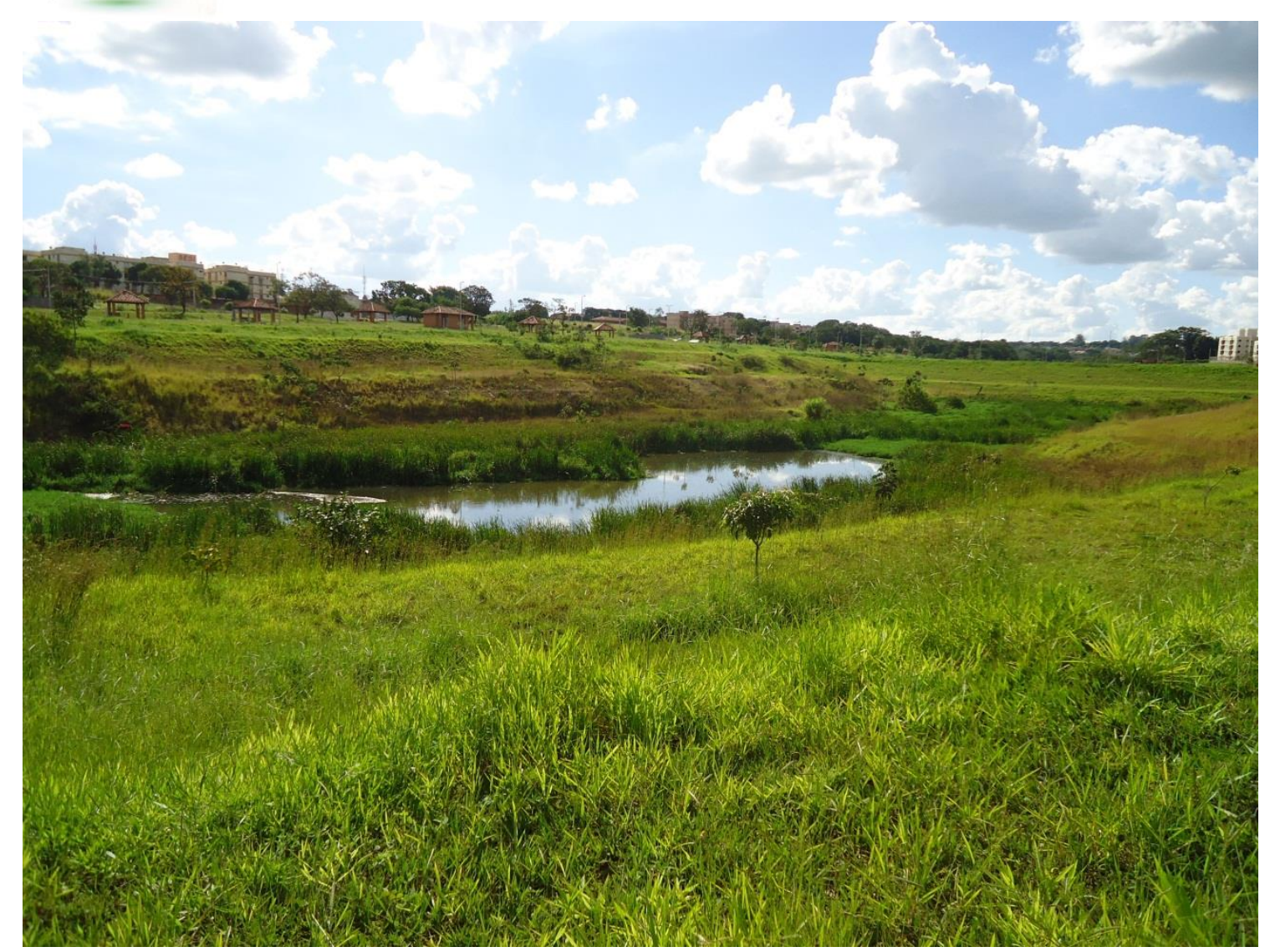

Figura 13: Reservatório emergencial e área alagada interna.

Fonte: Autores.

\section{CONSIDERAÇÕES FINAIS}

Os reservatórios foram construídos para juntos amortizar a vazão de pico durante o período de chuvas e possui comportas de regulação da vazão. Isso pode ser observado no ponto 03 no mês de novembro, onde na área se caracterizava por fortes precipitações e obteve um volume pequeno de $0,0118 \mathrm{~m}^{3} / \mathrm{s}$ escoando pelo canal do exultório do reservatório principal.

Relatos de moradores da região contam que a situação presenciada atualmente na região é bem melhor que a vivida há um tempo atrás, antes da construção dos reservatórios. Segundo eles os efeitos das enchentes hoje sobre seus imóveis, como por exemplo, a entrada de água para dentro dos terrenos é bem menos intensa e frequente do que antes da construção do sistema de amortecimento de cheias do Parque das Acácias.

As galerias construídas no centro da cidade para ampliar o sistema de macrodrenagem presente aumentaram a capacidade de escoamento das águas pluviais 
centrais minimizando o efeito das inundações, mas não deram solução total ao problema, já que parte do projeto Água Viva I e II ainda está em fase de execução. Todavia já ocorreram eventos de precipitações com inundações na área central, mesmo com toda parte da $3^{\underline{a}}$ galeria construída na Avenida Leopoldino de Oliveira, que já estava concluída e operando.

Sendo assim, a solução adotada minimizou os efeitos das inundações e não conseguiu dar uma solução definitiva ao problema presenciado, sendo então necessária a realização de estudos para que se possa definir qual a melhor solução para um fim definitivo no problema de enchentes que assola a população de Uberaba na área central.

\section{REFERÊNCIAS}

FELDMANN, F. GUIA DA ECOLOGIA: PARA ENTENDER E VIVER MELHOR A RELAÇÃO HOMEM NATUREZA. São Paulo, Editora Abril, 62 p., 1992.

REBOUÇAS A.C. ÁGUA DOCE NO MUNDO E NO BRASIL. IN: ÁGUAS DOCES NO BRASIL, Rebouças A.C.; Braga B.J.; Tundisi J.G. São Paulo, $3^{\circ}$ ed., Escrituras, 748 p., 2006.

STRASKRABA M.; TUNDISI J.G. RESERVOIR WATER QUALITY MANAGEMENT: GUIDELINES OF LAKE MANAGEMENT. KUSATSU, JAPAN: INTERNATIONAL LAKE ENVIRONMENTAL COMMITTEE, v.9, 227p., 1999.

VON SPERLING, M. INTRODUÇÃO À QUALIDADE DAS ÁGUAS E AO TRATAMENTO DE ESGOTOS. $2^{\circ}$ ed. UFMG, Belo Horizonte, 243p., 1996

CANHOLI, Aluísio. DRENAGEM URBANA E CONTROLE DE ENCHENTES. São Paulo: Oficina De Textos, 2005. $304 \mathrm{p}$ 